\title{
Synthesis and Crystal Structures of $\mathrm{Ni}(\mathrm{II}) /($ III) and $\mathrm{Zn}$ (II) Complexes with Schiff Base Ligands
}

\author{
Bon Kweon Koo* \\ Department of Chemistry, Catholic University of Daegu, Gyeongbuk 712-702, Korea. \\ ${ }^{*}$ E-mail: bkkoo@cu.ac.kr
}

(Received September 27, 2013; Accepted October 26, 2013)

Key words: $\mathrm{Ni}(\mathrm{II}) /(\mathrm{III}), \mathrm{Zn}(\mathrm{II})$, Schiff base, Crystal structure

Coordination polymers are of great interest due to their intriguing structural motifs and potential applications in optical, electronic, magnetic, and porous materials. ${ }^{1-3}$ The most commonly used strategy for designing such materials relies on the utilization of multidentate $\mathrm{N}$ - or Odonor ligands which have the capacity to bridge between metal centers to form polymeric structures. ${ }^{4}$ The Schiff bases with $\mathrm{N}, \mathrm{O}, \mathrm{S}$ donor atoms are an useful source as they are readily available and easily form stable complexes with most transition metal ions. ${ }^{5,6}$ Schiff bases are also important intermediates in synthesis of some bioactive compounds ${ }^{7}$ and are potent anti-bacterial, anti-fungal, anticancer and antiviral compounds. ${ }^{8}$

In this work, the Schiff bases, Hapb and Hbpb, derived from 2-acetylpyridene or 2-benzoylpyridine and benzhydrazide were taken as trifunctional $(\mathrm{N}, \mathrm{N}, \mathrm{O})$ monobasic ligand (Scheme 1). This ligand is of important because the $\pi$-delocalization of charge and the configurational flexibility of their molecular chain can give rise to a great variety of coordination modes. Although many metal-Schiff base complexes have been reported, the 1D, 2D, and 3D networks of coordination polymers linked through the bridging of ligands such as dicyanamide, $\mathrm{N}(\mathrm{CN})_{2}{ }^{-}$as coligand have been little published. ${ }^{9,10}$ In the process of working to extend the dimensionality of the metal-Schiff base complexes using benzilic acid as a bridging ligand, we obtained three simple metal (II)/(III) complexes of acetylpy-

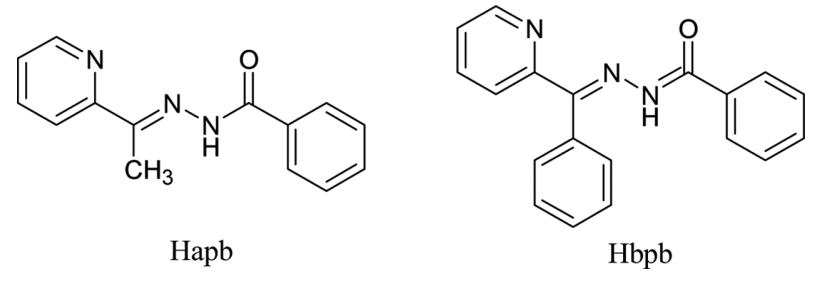

Scheme 1. Chemical structures of Schiff bases and their abbreviations. ridine/2-benzoyl pyridine based benzhydrazide ligand. Therefore, we report here the synthesis and crystal structures of the complexes.

\section{EXPERIMENTAL}

\section{Chemicals and Measurements}

All chemicals are comercially available and were used as received without further purification. Elemental analyses $(\mathrm{CHN})$ were performed on a Vario EL EA-Elementar Analyzer.

\section{Preparation of $\left[\mathrm{Zn}(\mathbf{b p b})_{2}\right](\mathbf{1})$}

To a methanolic solution $(30 \mathrm{~mL})$ of Hbpb ligand $(0.302 \mathrm{~g}$, $1.0 \mathrm{mmol})$ was added $\mathrm{Zn}\left(\mathrm{ClO}_{4}\right)_{2} \cdot 6 \mathrm{H}_{2} \mathrm{O}(0.372 \mathrm{~g}, 1.0 \mathrm{mmol})$. To the resulting pale yellow solution was added a methanolic solution $(3 \mathrm{~mL})$ of benzylic acid $(0.228 \mathrm{~g}, 1.0 \mathrm{mmol})$ and triethylamine $(0.152 \mathrm{~g}, 1.5 \mathrm{mmol})$. The solution turned to yellow and was refluxed for $3 \mathrm{~h}$ to yield yellow solid. The yellow solid was isolated by filtration and air-dried. The yellow filtrate was kept at room temperature to give yellow block crystals in good quality for X-ray crystallography. Yield: $63 \%(0.419 \mathrm{~g})$ based on Zn. Elemental Anal. Calcd. For $\mathrm{C}_{38} \mathrm{H}_{28} \mathrm{~N}_{6} \mathrm{O}_{2} \mathrm{Zn}$ : C, 68.52; H, 4.24; N, 12.62 . Found: C, 68.30; H, 4.57; N, 12.30\%.

\section{Preparation of $\left[\mathrm{Ni}(\mathrm{bpb})_{2}\right]$ (2)}

The compound was prepared similarly by the method described above for the preparation of $\mathbf{1}$, with use of $\mathrm{Ni}\left(\mathrm{ClO}_{4}\right)_{2} \cdot 6 \mathrm{H}_{2} \mathrm{O}$ instead of $\mathrm{Zn}\left(\mathrm{Cl}-\mathrm{O}_{4}\right)_{2} \cdot 6 \mathrm{H}_{2} \mathrm{O}$. Yield $58 \%$ $(0.382 \mathrm{~g})$ based on Ni. Elemental Anal. Calcd. for $\mathrm{C}_{38} \mathrm{H}_{28} \mathrm{~N}_{6} \mathrm{O}_{2} \mathrm{Ni}$ : C, 69.22; H, 4.28; N, 12.75. Found: $\mathrm{C}$, $68.72 ; \mathrm{H}, 4.52 ; \mathrm{N}, 12.28 \%$.

\section{Preparation of $\left[\mathrm{Ni}(\mathrm{apb})_{2}\right] \cdot \mathrm{ClO}_{4} \cdot \mathrm{CH}_{3} \mathrm{OH}(3)$}

The compound was prepared similarly by the method 
Table 1. Crystal data and structure refinement for complexes 1-3

\begin{tabular}{|c|c|c|c|}
\hline Complex & 1 & 2 & 3 \\
\hline Empirical formula & $\mathrm{C}_{38} \mathrm{H}_{28} \mathrm{~N}_{6} \mathrm{O}_{2} \mathrm{Zn}$ & $\mathrm{C}_{38} \mathrm{H}_{28} \mathrm{~N}_{6} \mathrm{O}_{2} \mathrm{Ni}$ & $\mathrm{C}_{29} \mathrm{H}_{28} \mathrm{~N}_{6} \mathrm{O}_{7} \mathrm{ClNi}$ \\
\hline Formula weight & 666.03 & 659.37 & 666.73 \\
\hline $\mathrm{T}(\mathrm{K})$ & $200(2)$ & $200(2)$ & $296(2)$ \\
\hline Crystal system & Triclinic & Triclinic & Monoclinic \\
\hline Space group & $\mathrm{P}-1$ & $\mathrm{P}-1$ & $\mathrm{P} 2(1) / \mathrm{n}$ \\
\hline$a(\AA)$ & $10.6428(6)$ & $10.7854(5)$ & $8.648(2)$ \\
\hline$b(\AA)$ & $12.5122(7)$ & $12.3971(5)$ & $10.625(2)$ \\
\hline$c(\AA)$ & $12.9696(7)$ & $12.6910(6)$ & $33.376(6)$ \\
\hline$\alpha\left(^{\circ}\right)$ & $66.234(1)$ & $66.726(1)$ & \\
\hline$\beta\left(^{\circ}\right)$ & $83.802(1)$ & $83.472(1)$ & $96.438(4)$ \\
\hline$\gamma\left({ }^{\circ}\right)$ & $83.602(1)$ & $82.652(1)$ & \\
\hline$V\left(\AA^{3}\right)$ & $1567.0(2)$ & $1542.3(1)$ & $3047.3(1)$ \\
\hline Z & 2 & 2 & 4 \\
\hline$\mu\left(\mathrm{mm}^{-1}\right)$ & 0.829 & 0.675 & 0.780 \\
\hline $\mathrm{F}(000)$ & 688 & 684 & 1380 \\
\hline$\theta\left(^{\circ}\right)$ & 1.72 to 28.29 & 1.80 to 28.30 & 1.23 to 28.31 \\
\hline Absorption correction & none & none & $\begin{array}{l}\text { multi-scan } \\
\mathrm{T}_{\min }=0.814, \mathrm{~T}_{\max }=0.901\end{array}$ \\
\hline Limiting indices & $-14 \leq \mathrm{h} \leq 14,-16 \leq \mathrm{k} \leq 16,-10 \leq \mathrm{k} \leq 17$ & $-14 \leq \mathrm{h} \leq 14,-16 \leq \mathrm{k} \leq 16,-16 \leq \mathrm{l} \leq 10$ & $-10 \leq \mathrm{h} \leq 11,-14 \leq \mathrm{k} \leq 13,-44 \leq \mathrm{l} \leq 39$ \\
\hline Reflections collected & 11790 & 11603 & 22130 \\
\hline Independent reflections & $7684[\mathrm{R}(\mathrm{int})=0.0464]$ & $7545[\mathrm{R}(\mathrm{int})=0.0459]$ & $7523[\mathrm{R}(\mathrm{int})=0.0642]$ \\
\hline Observed reflections $[I \geq 2 \sigma(I)]$ & 3588 & 4017 & 4094 \\
\hline Goodness-of-fit on $F^{2}$ & 0.890 & 1.092 & 1.103 \\
\hline$R_{1}[I \geq 2 \sigma(I)]$ & 0.0523 & 0.0691 & 0.0520 \\
\hline$w R_{2}[I \geq 2 \sigma(I)]$ & 0.0690 & 0.1055 & 0.1154 \\
\hline$R_{1}$ & 0.1332 & 0.1399 & 0.1208 \\
\hline$w R_{2}$ & 0.1013 & 0.1706 & 0.1617 \\
\hline Largest peak and hole $\left(\mathrm{e} \AA^{-3}\right)$ & 0.844 and -1.384 & 1.273 and -2.108 & 0.645 and -0.624 \\
\hline
\end{tabular}

described above for the preparation of $\mathbf{1}$, with use of $\mathrm{Ni}\left(\mathrm{ClO}_{4}\right)_{2} \cdot 6 \mathrm{H}_{2} \mathrm{O}$ and $\mathrm{Hapb}$ instead of $\mathrm{Zn}\left(\mathrm{ClO}_{4}\right)_{2} \cdot 6 \mathrm{H}_{2} \mathrm{O}$ and $\mathrm{Hbpb}$ ligand, respectively. Yield 65\% (0.432 g) based on Ni. Elemental Anal. Calcd. for $\mathrm{C}_{29} \mathrm{H}_{28} \mathrm{~N}_{6} \mathrm{O}_{7} \mathrm{CINi}$ : C, 52.24; H, 4.23; N, 12.61. Found: C, 51.85; H, 4.48; N, 12.31\%.

\section{X-ray Structure Determination}

Single crystals of 1-3 were obtained by the method described in the above procedures. Structural measurement for the complexes were performed on a Bruker SMART APEX CCD diffractometer using graphite monochromatized Mo-K $\alpha$ radiation $(\lambda=0.71073 \AA)$ at the Korea Basic Science Institute. The structures were solved by direct method and refined on $\mathrm{F}^{2}$ by full-matrix least-squares procedures using the SHELXTL programs. ${ }^{11}$ All non-hydrogen atoms were refined using anisotropic thermal parameters. The hydrogen atoms were included in the structure factor calculation at idealized positions by using a riding model, but not refined. Images were created with the ORTEP ${ }^{12}$ or
DIAMOND program. ${ }^{13}$ The crystallographic data for complexes 1-3 are listed in Table 1.

\section{RESULTS AND DISCUSSION}

The complexes of 1-3 were prepared from the methanolic solution of $\mathrm{M}\left(\mathrm{ClO}_{4}\right)_{2} \cdot \mathrm{xH}_{2} \mathrm{O}(\mathrm{M}=\mathrm{Ni}$, and $\mathrm{Zn})$, Schiff base ligand, and bnzilic acid. Our first aim in this work was to obtain the coordination polymers which metal centers are bridged by the benzilic acid as mixed ligand. However, the benzilic acid present in the initial reaction mixture was not found in the crystalline product. Unfortunately, attempts to obtain the product containing the benzilic acid and to improve yields by varying stoichiometry, temperature, and other reaction parameters proved to be generally unsuccessful.

\section{Description of the Structures}

The molecular structure of complex 1 consists of one 


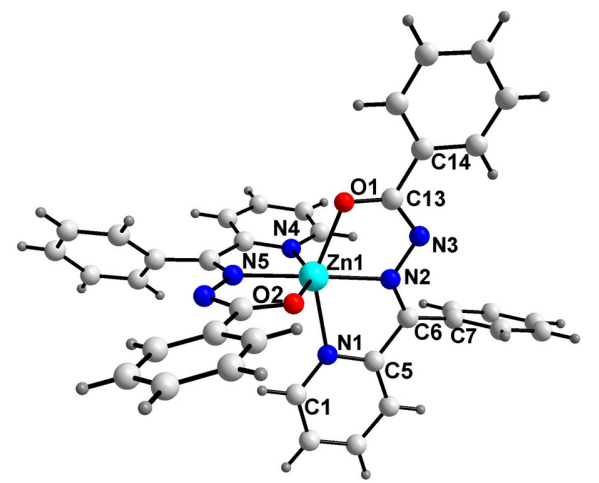

(a)

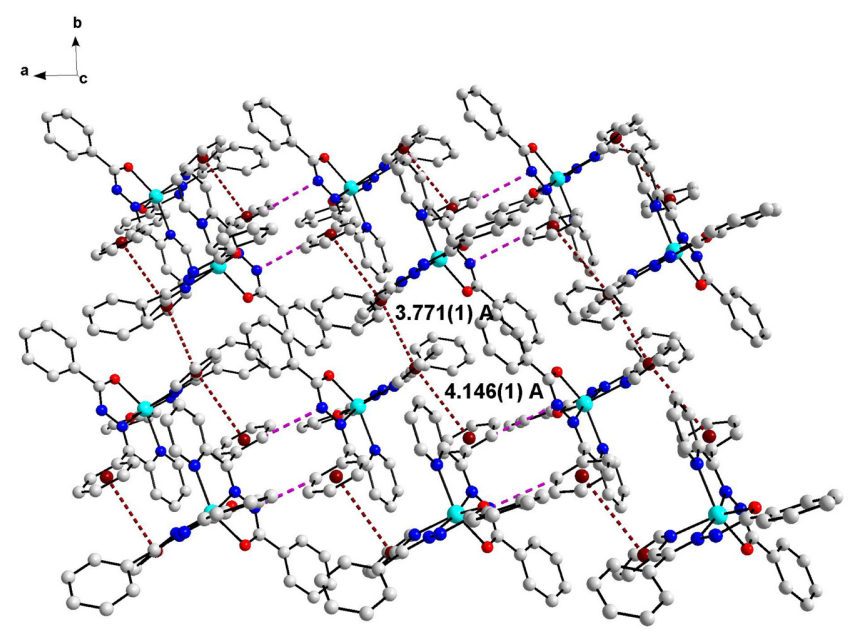

(c)

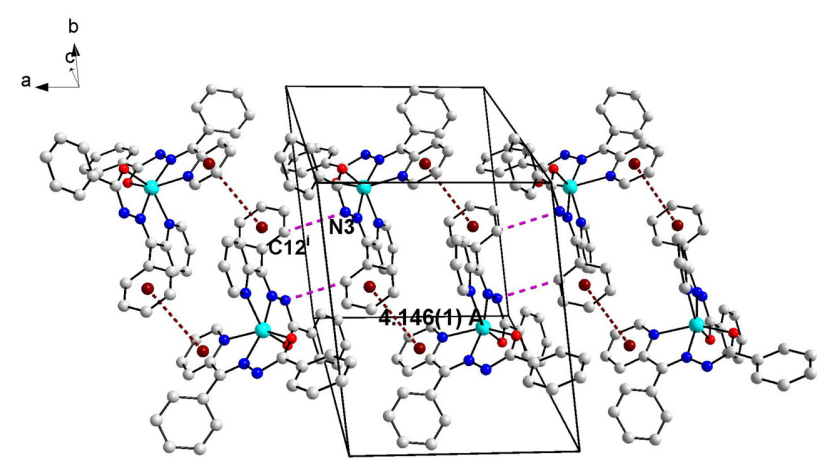

(b)

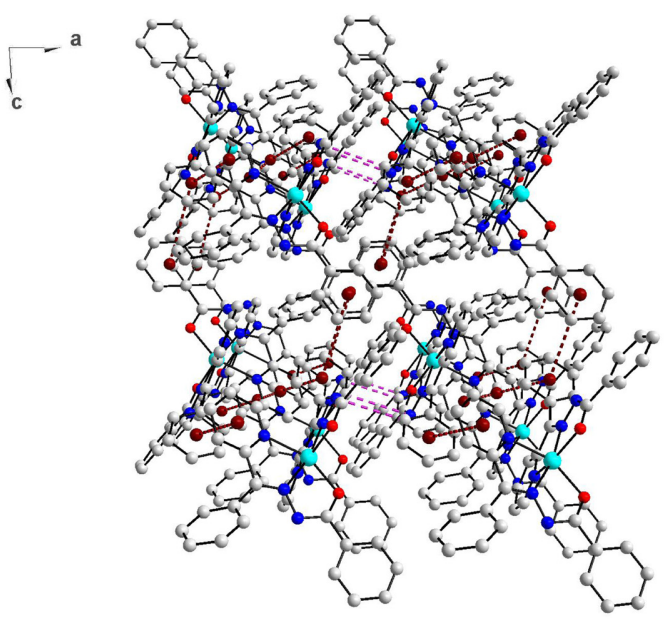

(d)

Figure 1. (a) Molecular structure of complex 1 with atomic labeling. (b) The $1 \mathrm{D}$ chain formed by H-bond and $\pi-\pi$ interactions in 1 along the $a$-axis. Geometric details describing the H-bond operating in the crystal structure: $\mathrm{C} 12{ }^{\mathrm{i}}-\mathrm{H} 12 \cdots \mathrm{N} 3=2.46 \AA$ with angle at $\mathrm{H} 12=139.4^{\circ}$ for symmetry operation i: $2-x, 1-y, 1-z$. (c) The $2 \mathrm{D}$ layer framework of complex $\mathbf{1}$ formed by H-bond and $\pi-\pi$ interactions. (d) Packing diagram of complex 1. The hydrogen bonds and $\pi-\pi$ interactions have been shown as dashed and dotted lines, respectively. All H-atoms in (b)-(d) have been omitted for clarity.

$\mathrm{Zn}(\mathrm{II})$ ion and two coordinated $\mathrm{bpb}^{-}$ligands (Fig. 1(a)). $\mathrm{Zn}(\mathrm{II})$ ion center is six-coordinated by four nitrogen atoms $(\mathrm{N} 1, \mathrm{~N} 2, \mathrm{~N} 4, \mathrm{~N} 5)$ and two oxygen atoms $(\mathrm{O} 1, \mathrm{O} 2)$ from two bpb ligands. The $\mathrm{Zn}-\mathrm{N}$ bond lengths are slightly longer than the $\mathrm{Zn}-\mathrm{O}$ distances. The basal plane (N2N4N5O2) is nearly planar (mean deviation $0.053(3) \AA$ ) and the $\mathrm{Zn} 1$ is displaced by 0.041 (1) from the plane toward O1. The structural data are listed in Table 2 and are in agreement with those of the $\mathrm{Zn}$ (II) complexes which exhibit the similar geometry. ${ }^{14,15}$ Three planes [N1C1-C5, C7-C12 and $\mathrm{C} 14-\mathrm{C} 19]$ in $^{-} \mathrm{bpb}^{-}$are nearly planar with the largest deviations of atoms from the mean planes: $\mathrm{C} 1 ; 0.005(4), \mathrm{C}$; $-0.003(5)$, and $\mathrm{C} 17 ; 0.003(4) \AA$, respectively. The dihedral angles between two phenyl rings (C7-C12 and C14C19) and between two planes N1C1-C5 and C14-C19 are $71.97(13)$ and $18.39(11)^{\circ}$, respectively.
The principal feature of the crystal packing is the formation of a three-dimensional network by $\mathrm{C}-\mathrm{H} \cdots \mathrm{N}$ and $\pi \cdots \pi$ contacts. Two monomeric molecules in the unit cell are linked by $\pi \cdots \pi$ stacking between pyridine and phenyl rings of neighboring molecules with inter-ring distance of 4.146 (1) $\AA$. The unit cell is further extended by intermolecular

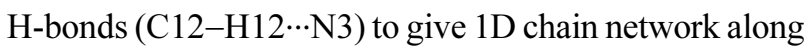
$a$-axis (Fig. 1(b)). This chains also constructs 2D plane ( $a b$-plane) by the $\pi \cdots \pi$ stacking between adjacent pyridine rings (centroid-to-centroid distance of 3.771(1) Å) (Fig. 1(c)). The 3D supramolecular structure is formed by inter-layer face-to-face $\pi \cdots \pi$ stacking $(4.352(1) \AA$ ) between phenyl rings of adjacent $2 \mathrm{D}$ layers along $c$-axis. The packing diagram is shown in Fig. 1(d).

The complex $\mathbf{2}$ has basically the same structure of $\mathbf{1}$ (Fig. 2). Nickel(III) ion exhibits a distorted octahedral 
Table 2. Selected bond lengths $(\AA)$ and angles $\left({ }^{\circ}\right)$ for complexes 1-3

\begin{tabular}{llll}
\hline Complex 1 & & & \\
\hline Zn1-O2 & $2.056(2)$ & Zn1-O1 & $2.104(3)$ \\
Zn1-N5 & $2.076(3)$ & Zn1-N2 & $2.082(3)$ \\
Zn1-N4 & $2.210(3)$ & Zn1-N1 & $2.213(3)$ \\
O1-C13 & $1.271(4)$ & N3-C13 & $1.367(4)$ \\
O2-Zn1-N5 & $75.8(1)$ & O2-Zn1-N2 & $116.1(1)$ \\
N5-Zn1-N2 & $166.9(1)$ & O2-Zn1-N4 & $150.3(1)$ \\
N5-Zn1-N4 & $74.5(1)$ & N2-Zn1-N4 & $93.7(1)$ \\
N2-Zn1-N1 & $74.3(1)$ & O1-Zn1-N1 & $148.9(1)$ \\
\hline Complex 2 & & & \\
\hline Ni1-O2 & $2.063(3)$ & Ni1-O1 & $2.082(3)$ \\
Ni1-N5 & $2.003(4)$ & Ni1-N2 & $2.002(4)$ \\
Ni1-N4 & $2.098(4)$ & Ni1-N1 & $2.122(4)$ \\
O1-C13 & $1.277(6)$ & N3-C13 & $1.348(6)$ \\
N2-Ni1-N5 & $172.7(2)$ & N2-Ni1-O2 & $109.6(2)$ \\
N5-Ni1-O2 & $77.1(2)$ & N2-Ni1-O1 & $76.8(2)$ \\
N2-Ni1-N4 & $95.1(2)$ & N5-Ni1-N4 & $78.3(2)$ \\
O2-Ni1-N4 & $155.2(2)$ & O1-Ni1-N1 & $154.8(2)$ \\
\hline Complex 3 & & & \\
\hline Ni1-N2 & $1.983(3)$ & Ni1-N5 & $2.016(3)$ \\
Ni1-O1 & $2.072(2)$ & Ni1-N1 & $2.090(3)$ \\
Ni1-N4 & $2.109(3)$ & Ni1-O2 & $2.153(2)$ \\
N3-C8 & $1.331(4)$ & C8-O1 & $1.287(4)$ \\
N2-Ni1-N5 & $174.7(1)$ & O1-Ni1-N1 & $154.6(1)$ \\
N2-Ni1-N4 & $99.2(1)$ & N5-Ni1-N4 & $76.6(1)$ \\
N2-Ni1-O2 & $108.4(1)$ & N5-Ni1-O2 & $76.0(1)$ \\
N4-Ni1-O2 & $152.3(1)$ & & \\
\hline & & & \\
\hline
\end{tabular}

environments with the cis- and trans-L-Ni-L angles in the range of $76.8(2)-109.6(2)^{\circ}$ and $154.8(2)-172.7(2)^{\circ}$, respectively (Table 2), compared to the complex 1 (cis- and trans$\mathrm{L}-\mathrm{Zn}-\mathrm{L}$ angles in the range of $74.3(1)-116.1(1)^{\circ}$ and 148.9(1)-166.9 (1) ${ }^{\circ}$, respectively). The deviation from the ideal values for the octahedral structure is relatively small and more close to the octahedral compared to the complex 1 . The average bond distances of $\mathrm{Ni}-\mathrm{N}$ and $\mathrm{Ni}-\mathrm{O}$ are 2.056(4) and 2.073(3) $\AA$, respectively. The distances are slightly shorter than the distances $(\mathrm{Zn}-\mathrm{N}=2.145(3)$ and $\mathrm{Zn}-\mathrm{O}=2.080(3) \AA$ ) of complex 1. Most notably, the distance of $\mathrm{Ni}-\mathrm{N}$ is smaller than $\mathrm{Ni}-\mathrm{O}$ bond distances, contrast to the complex $\mathbf{1}$.

Complex $\mathbf{2}$ is also consolidated into a three-dimensional network by a $\mathrm{C}-\mathrm{H} \cdots \mathrm{N}\left(\mathrm{C} 8^{\mathrm{i}}-\mathrm{H} 8 \cdots \mathrm{N} 3^{\mathrm{ii}}=2.52 \AA\right.$ and $\mathrm{C} 8^{\mathrm{i}} \cdots \mathrm{N} 3^{\mathrm{ii}}=3.28(1) \AA$ with angle at $\mathrm{H} 8=141^{\circ}$ for symmetry operation $\mathrm{i}: \mathrm{x}, 1+\mathrm{y},-1+\mathrm{z}$; ii: $2-\mathrm{x}, 2-\mathrm{y},-\mathrm{z}$ ) and $\pi \cdots \pi$ interactions. Two monomeric molecules in the unit cell are linked by $\pi \cdots \pi$ stacking between pyridine and phenyl rings of neighboring molecules with inter-ring distance of 4.157(1)

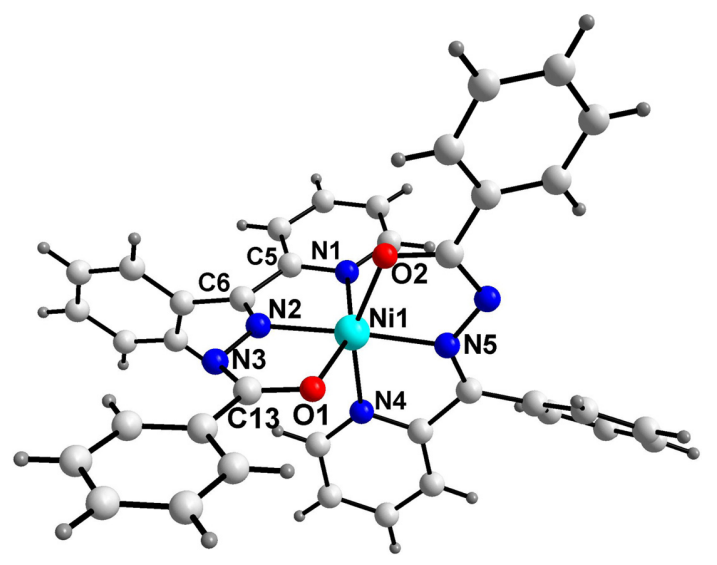

Figure 2. Molecular structure of complex 2 with atomic labeling.

$\AA ̊$ and intermolecular $\mathrm{H}$-bonds $\left(\mathrm{C} 8^{\mathrm{i}}-\mathrm{H} 8 \cdots \mathrm{N} 3^{\mathrm{ii}}\right)$ to give 1D chain network along $a$-axis as shown in complex 1 . The chains constructs $2 \mathrm{D}$ framework by the $\pi \cdots \pi$ stacking between adjacent pyridine rings (centroid-to-centroid distance of 3.815(1) $\AA$ ) and finally, 3D network is accomplished by inter-layer face-to-face $\pi \cdots \pi$ stacking (4.400(1) $\AA$ ) between phenyl rings of adjacent 2D layers along $c$ axis.

While, complex 3 consists of one Ni(III) ion, two coordinated apb ligands, one perchlorate ion, and one solvent methanol molecule, respectively (Fig. 3(a)). Here, the oxidation state of nickel is +3 in contrast to $\mathrm{Ni}$ (II) of starting material. This oxidation to $\mathrm{Ni}$ (III) can be assumed that the starting $\mathrm{Ni}$ (II) salt undergoes aerial oxidation in the presence of the Schiff base ligand in methanolic solution during preparation of the complex. ${ }^{16-18}$

The structure of complex 3 is similar to those of the complexes 1 and 2 with $\mathrm{bpb}^{-}$ligand. Two planes of $\mathrm{apb}^{-}$ ligand, N4C15-C19 and C23-C28, are nearly plane with $\mathrm{rms}=0.003(4)$, and $0.006(5) \AA$, respectively. The dihedral angle between them is $15.1(1)^{\circ}$. While, the dihedral angle between two pyridine planes (N1C1-C5 and N4C15-C19) of two apb ligands is $89.9(1)^{\circ}$. The distances and bond angles are listed in Table 2. The structural data are similar to those of the Mn (II) and $\mathrm{Zn}$ (II) complexes with apb ligand, respectively. ${ }^{14}$

As shown in Fig. 3(b), the monomeric units construct $2 \mathrm{D}$ network by $\pi \ldots \pi$ stacking between pyridine and phenyl rings with inter-ring distance of 3.639(1) ( $a$-axis) and 4.114(1) Å (b-axis), respectively. In contrast to complexes 1 and 2 , there is not intermolecular H-bonding which construct 3D net work. For all complexes, the relatively short C13-N3 (for 1 and 2) and C8-N3 (for 3) bond distances (normal single bond is $1.52 \AA$ ), ${ }^{19}$ coupled with the length- 


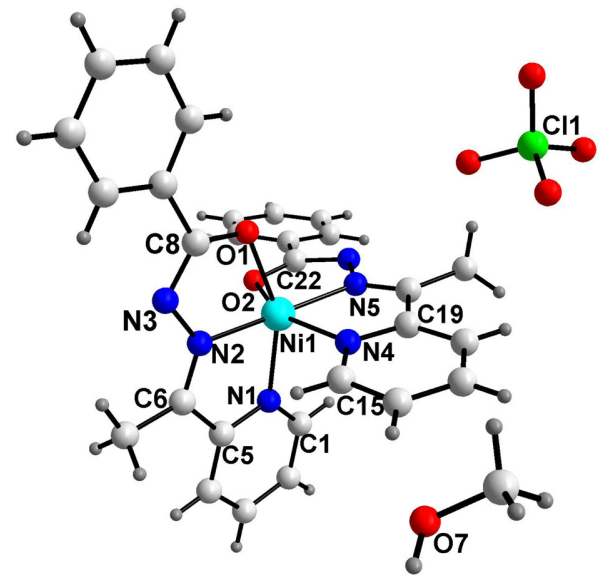

(a)

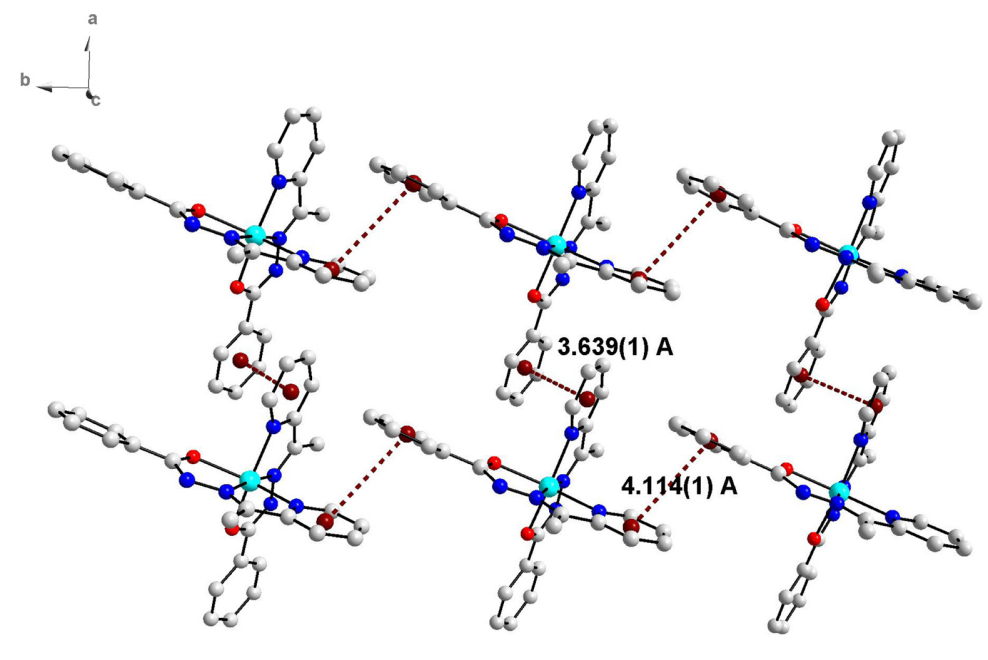

(b)

Figure 3. (a) Molecular structure of complex 3 with atomic labeling. (b) $2 \mathrm{D}$ layer in complex 3. All $\mathrm{H}$ atoms, $\mathrm{CH}_{3} \mathrm{OH}$, and $\mathrm{ClO}_{4}{ }^{-}$have been omitted for clarity.

ened $\mathrm{C} 13-\mathrm{O} 1$ (for $\mathbf{1}$ and 2) and $\mathrm{C} 8-\mathrm{O} 1$ (for 3) distances which is typical of ketonic linkage $(1.23 \AA)^{20,21}$ indicate that the ligands act as enol form.

In conclusion, by the reactions of $\mathrm{Ni}(\mathrm{II}) / \mathrm{Zn}$ (II) ions and Schiff base ligands, three new metal(II)/(III) complexes, $\left[\mathrm{Zn}(\mathrm{bpb})_{2}\right](\mathbf{1}),\left[\mathrm{Ni}(\mathrm{bpb})_{2}\right](\mathbf{2})$, and $\left[\mathrm{Ni}(\mathrm{apb})_{2}\right] \cdot \mathrm{ClO}_{4} \cdot \mathrm{CH}_{3} \mathrm{OH}$ (3), have been synthesized. In each complex, metal ion is six-coordinated with $\mathrm{N} 4 \mathrm{O} 2$ donors. The Schiff base is coordinated to metal(II)/(III) ions as a trifunctional ligand. The structures are further extended into supramolecular framework by hydrogen bonds and $\pi \ldots \pi$ stacking interactions. Unfortunately, it has failed to obtain the polymeric complexes of Schiff base through benzilic acid in this work. The development of synthetic routes to the systems containing Schiff base is still required for the rational design and synthesis.

Acknowledgments. This work was supported by the 2012 Research Fund of Catholic University of Daegu. The author also acknowledges the Korea Basic Science Institute for providing the crystal structure results.

Supporting Information. Crystallographic data in CIF format have been deposited with the Cambridge Structural Database CCDC 927522 (for 1), 927523 (for 2), and 927521 (for 3), respectively. These data can be obtained free of charge at www.ccdc.cam.ac.uk/conts/retrieving.html (or from the Cambridge Crystallographic Data Centre, 12, Union Road, Cambridge CB2 1EZ, UK; Fax: +44-1223/336-033; E-mail: deposit@ccdc.cam.ac.uk).

\section{REFERENCES}

1. Yaghi, O. M.; O’Keeffe, M.; Ockwig, N. W.; Chae, H. K.; Eddaoudi, M.; Kim, J. Nature 2003, 423, 705.

2. Hagrman, P. J.; Hagrman, D.; Zubieta, J. Angew. Chem. Int. Ed. 1999, 38, 2638.

3. Erxleben, A. Coord. Chem. Rev. 2003, 246, 203.

4. Suna,Y.-X.; Youb Z.-L. Z. Anorg. Allg. Chem. 2006, 632, 1566.

5. Shaabani, B.; Khandar, A. A.; Dusek, M. M.; Mahmoudi, P. F. Inorg. Chim. Acta 2013, 394, 563.

6. Nayak, S.; Gamez, P.; Kozlevcar, B.; Pevec, A.; Roubeau, O.; Dehnen, S.; Reedijik, J. Polyhedron 2010, 29, 2291.

7. Mohamad, G. G.; Omar, M. M.; Ibrahim, A. A. Spectrochim. Acta, Part A 2010, 75, 678.

8. Rapheal, P. F.; Manoj, E.; Kurup, M. R. P.; Suresh, E. Polyhedron 2007, 26, 607.

9. Yue, Y.-F.; Gao, E.-Q.; Fang, C.-J.; Xu, S.; Yan, C.-H.; J. Mol. Struct. 2007, 841, 67.

10. Karmakar, R.; Choudhury, C. R.; Hughes, D. L.; Yap, G.. P. A.; Fallah, M. S. El.; Desplanches, C.; Sutter, J.-P.; Mitra, S. Inorg. Chim. Acta 2006, 359, 1184.

11. Sheldrick, G. M. SHELXTL: version 6; Bruker AXS Inc.; Madison, Wisconsin, USA, 2001.

12. Farrugia, L. J. J. Appl. Cryst. 1997, 30, 565.

13. Brandenburg, K. DIAMOND: version 2.1; Crystal Impact GbR: Bonn, Germany, 1998.

14. Jang,Y. J.; Lee, U.; Koo, B. K. Bull. Korean Chem. Soc. 2005, 26, 925.

15. Anitha, C.; Sheela, C. D.; Tharmaraj, P. S.; Raja, J. Spectrochim. Acta, Part A 2012, 98, 35.

16. Pinho, D.; Gomes, P.; Freire, C.; Castro, B. Eur. J. Inorg. Chem. 2001, 1483. 
17. Franks, M.; et al. Inorg. Chem. 2013, 52, 660.

18. Freire, C.; Castro, B. Polyhedron 1998, 17, 4227.

19. Dutta, S.; Basy, P.; Chakravorty, A. Inorg. Chem. 1991, 30, 4031.

20. Mangalam, N. A.; Sivakumar, S.; Sheeja, S. R.; Kurup, M.
R. P.; Tiekink, E. R. T. Inorg. Chim. Acta 2009, 362, 4191.

21. Patole, J.; Sandbhor, U.; Padhye, S.; Deobagkar, D. N.; Anson, C. E.; Powell, A. Bioorg. Med. Chem. Lett. 2003, 13, 51 . 